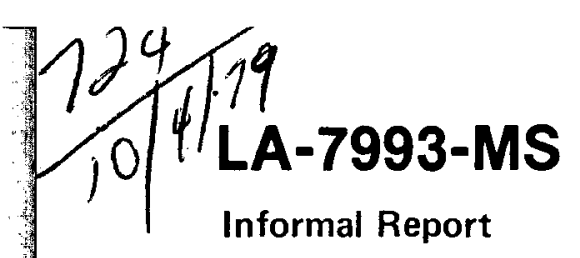

Informal Report

\section{Thermal Gradients and Heat Flow Data in Colorado and Wyoming:}

A Preliminary Report 
This report was not edited by the Technical Information staff.

Work supported by the US Department of Energy, Division of Geothermal Energy. Contract No. 3896G.

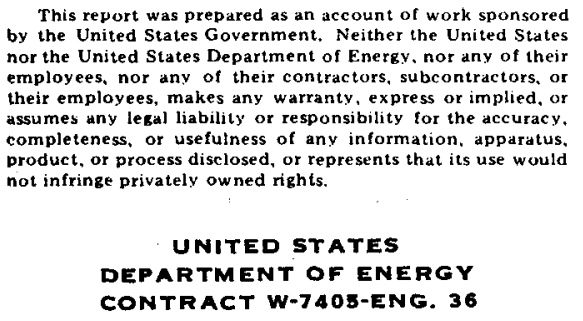


LA-7993-MS

Informal Report

UC-66a

Issued: August 1979

\title{
Thermal Gradients and Heat Flow Data in Colorado and Wyoming:
}

\author{
A Preliminary Report
}

\author{
E. R. Decker* \\ G. J. Bucher*
}

"Department of Geology, University of Wyoming, Casper, WY 82601.

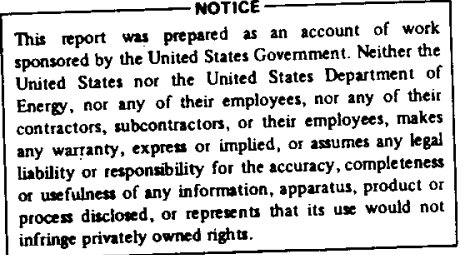


THERMAL GRADIENTS AND HEAT FLOW DATA

IN COLORADO AND WYOMING: A PRELIMINARY REPORT

by

E. R. Decker and G. J. Bucher

\begin{abstract}
Temperature gradient data and heat flow data are compiled for 23 core and rotary drill holes in the Rocky Mountains of Colorado and Wyoming. Gradients range from $10.7^{\circ} \mathrm{C} / \mathrm{km}$ in the Medicine Bow Mountains, Wyoming, to $40.1^{\circ}$ $\mathrm{C} / \mathrm{km}$ in the San Juan Mountains, Colorado. Uncorrected heat flow ranges from 1.1 to HFU at Rawlins, Wyoming to 6.1 at Rico, Colorado.
\end{abstract}

\title{
I. INTRODUCTION
}

This report refers to contracts N28-3896G-1 and N28-4934H-1 (directed by E. R. Decker, University of Wyoming). Research to date has emphasized temperature depth measurements in 23 core and rotary drill holes in Colorado and Wyoming. Thermal gradients and heat flow values have been compiled for many of these holes. Related field work involved contract casing of a deep $(\sim 670 \mathrm{~m})$ core hole in the San Juan Mountains in southwestern Colorado.

\section{WORK IN PROGRESS}

Radiogenic heat production values are being determined for many of the deep holes that penetrated intrusive rocks in. the southern Rocky Mountains (see Table II).

Core and/or chip samples for thermal conductivity measurements for many of these holes will be available in the near future.

\section{DATA}

Figures 1-23 are plots of temperatures and depths in 23 drill holes that are being analyzed under the contracts. Table $I$ is a compilation of gradients for nine of these holes. Observed ( $q_{\text {unc }}$ ) and corrected ( $q_{c o r}$ ) heat flow data for 12 of these localities are listed in Table II, as are hole locations to the nearest 
minute. The corrected heat flow values directly follow Birch's (1950) correction for three-dimensional topography'. Each correction was made for terrain for a lateral distance equal to 20 times the depth of each hole.

Figures 1-23 and Tables I and II represent the most reliable data that we have been able to obtain. These data will yield publishable heat flow values. Although many other sites (about 20) have been visited for temperature-depth measurements, the data for them cannot be used for reliable heat flow calculations because the holes were blocked at very shallow depths.

TABLE I

SUMMARY OF PRELIMINARY GRADIENT VALUES FOR DRILL HOLES

Colorado

Elkhorn

Winfield

Chicago Basin

v. Basin

Det Norte

Wyoming

Sand Lake

(Medicine Bow Mtns)

Rawlins (Red Rim)

Douglas

(Powder River Basin)

\#LCI

\#LC2
34.4

10.7

16.4

33.8

1. Francis Birch, "Flow of heat in the Front Range, Colorado," Geol. Soc. Am. Bu11. 61, 567-630 (1950). 
TABLE 2

SUMMARY OF PRELIMINARY HEAT FLOW VALUES

Locality

Colorado

Elkhorn ${ }^{\mathrm{a}}$

Apex

Winfield

Chicago Basin ${ }^{a}$

v. Basina, b

Redwel1 Basin

Rico

Del Norte

Summitville $e^{\mathrm{a}}$

Wyoming

Sand Lake

Al bany ${ }^{\mathrm{a}}$

Rawl ins
Location

W. Long., N. Lat.
Heat Flow

HFU

$q_{\text {unc }}$

2.13

1.50

1.42

2.88

2.97

2.84

$106^{\circ} 27^{\prime}, 38^{\circ} 59^{\prime}$

2.69

2.45

$107^{\circ} 37^{\prime}, 37^{\circ} 36^{\prime}$

$107^{\circ} 35^{\prime}, 37^{\circ} 34^{\prime}$

1.91

2.44

2.11

2.29

3.26

3.62

$107^{\circ} 3^{\prime}, 38^{\circ} 54^{\prime}$

$5.2-5.9$

$108^{\circ} 1^{\prime}, 37^{\circ} 42^{\prime}$

$5.2-6.1$

$108^{\circ} 2^{\prime}, 37^{\circ} 42^{\prime}$

2.68

2.69

$106^{\circ} 22^{\prime}, 37^{\circ} 47^{\prime}$

2.3

2.4

$106^{\circ} 36^{\prime}, 37^{\circ} 26^{\prime}$

1.4

$1.4-1.5$

$106^{\circ} 11^{\prime}, 41^{\circ} 12^{\prime}$

1.60

1.62

$107^{\circ} 27^{\prime}, 41^{\circ} 44^{\prime}$

1.1

1.1

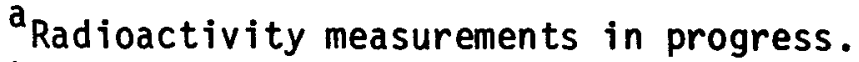

${ }^{b}$ Cased with monies provided by LASL contract.
} 


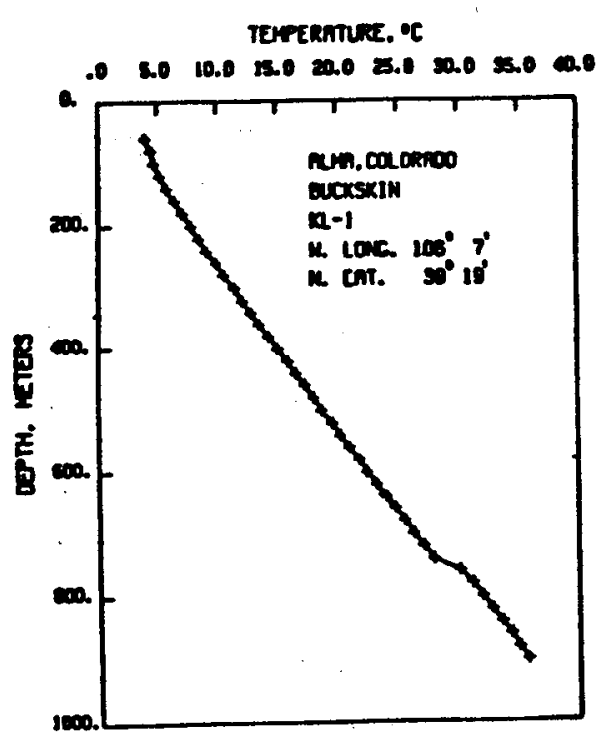

Fig. 1

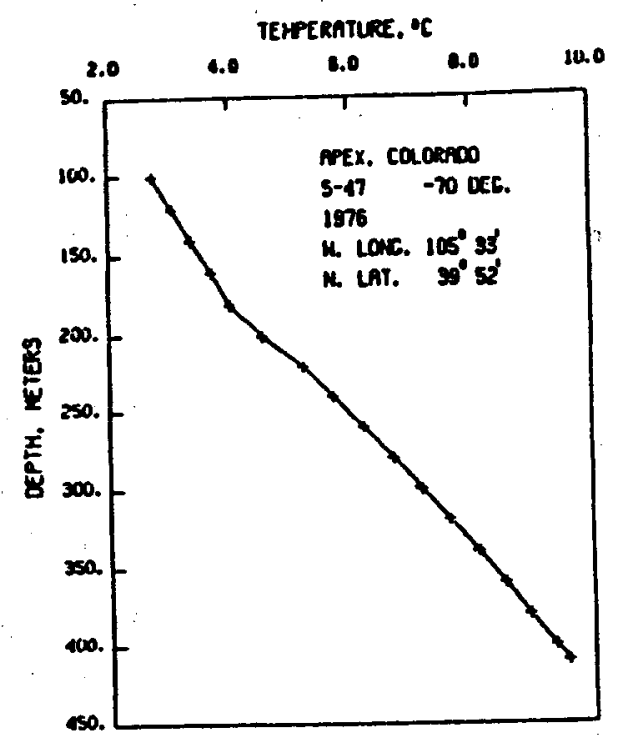

Fig. 2

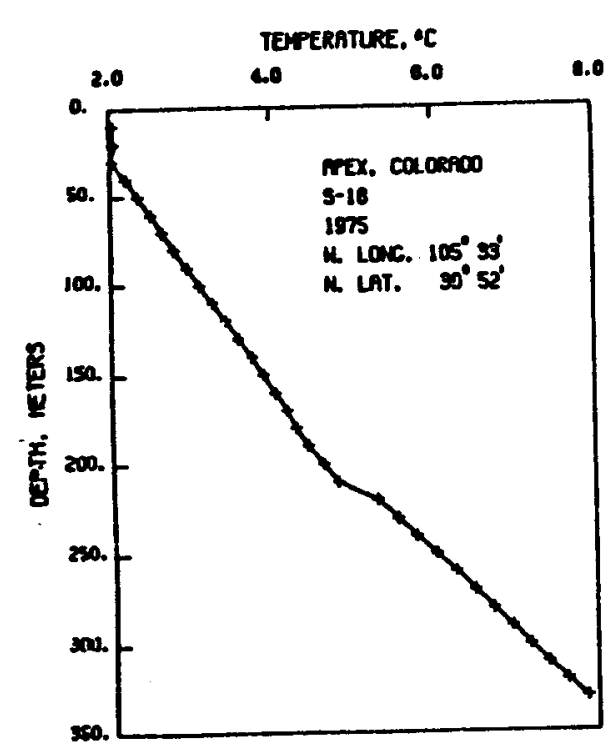

Fig. 3

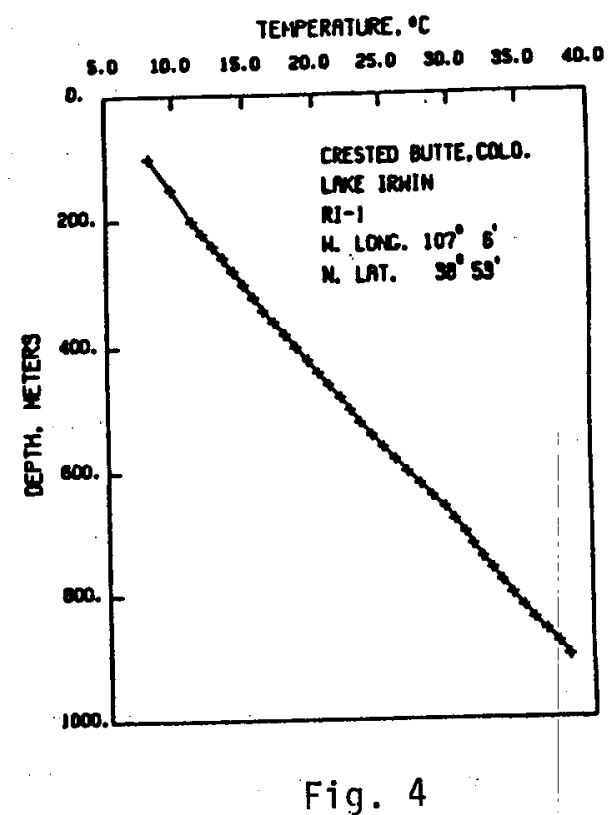

Figs. 1-23. Temperatures as functions of depth in reliable drill holes. 


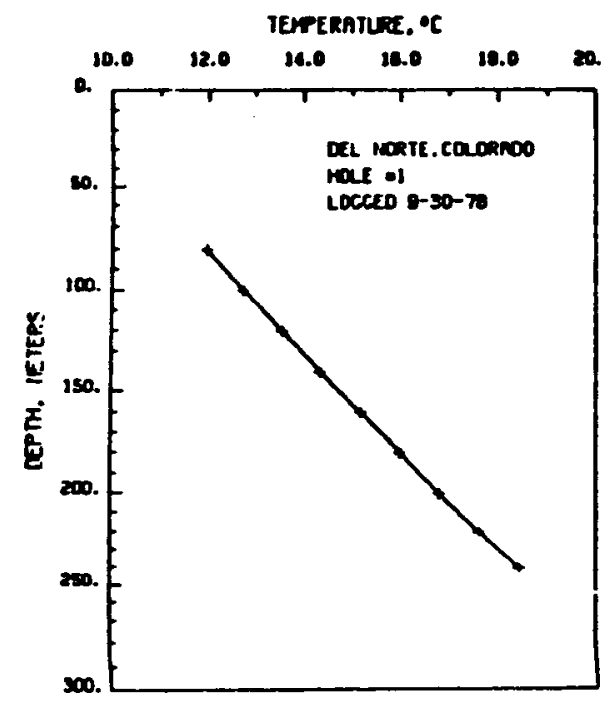

Fig. 5

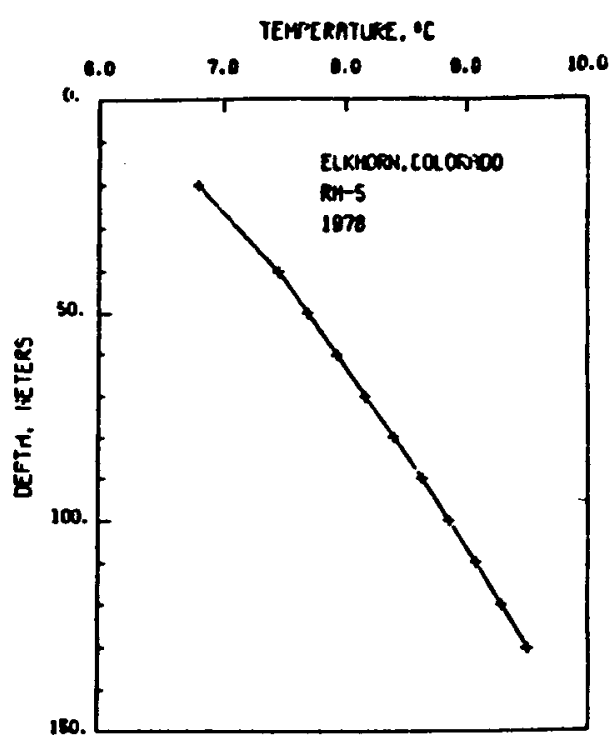

Fig. 6

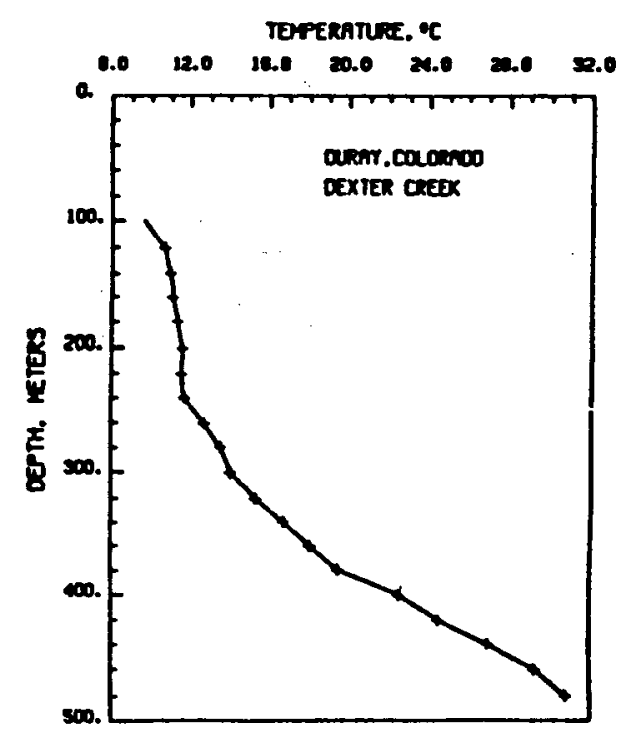

Fig. 7

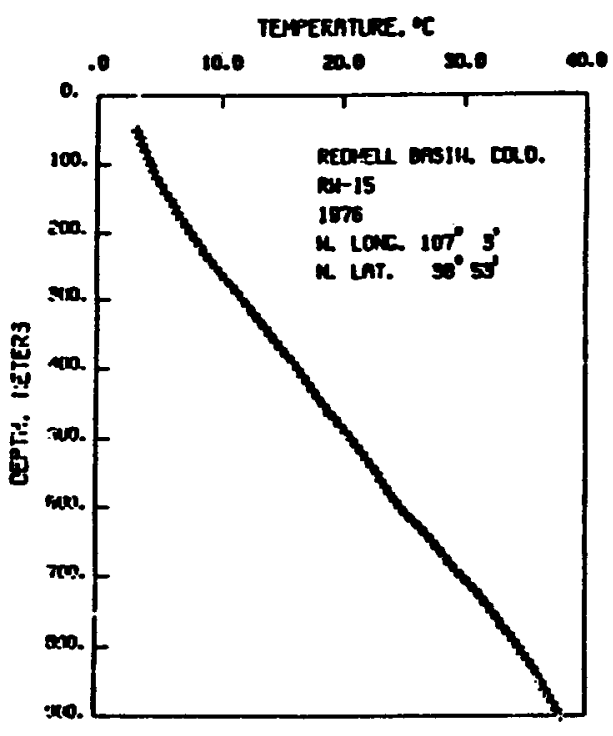

Fig. 8 


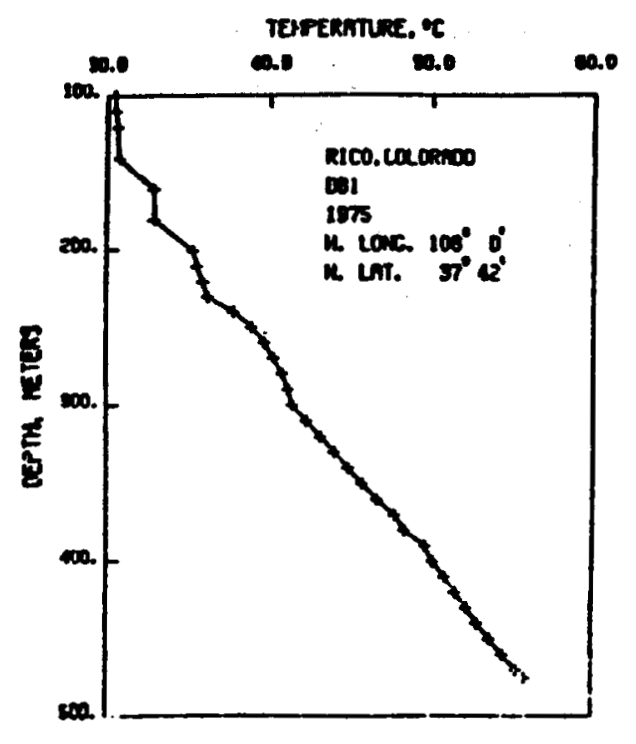

Fig. 9

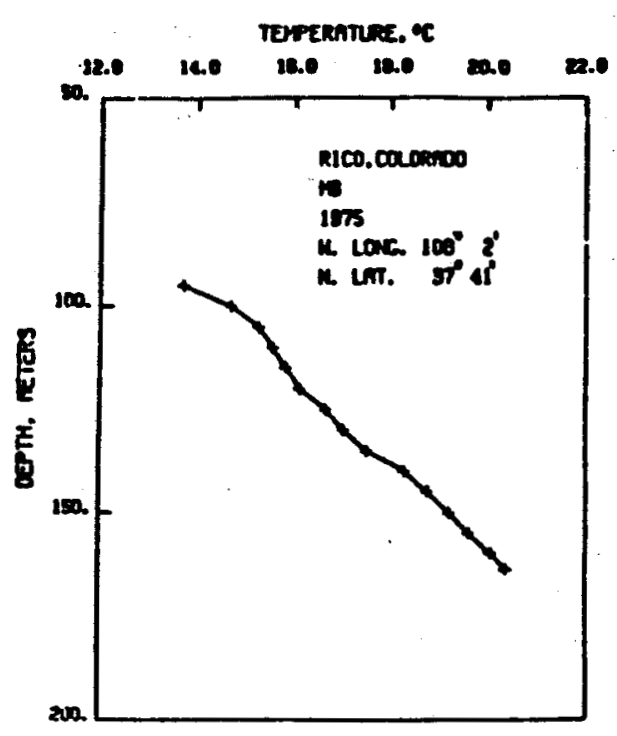

Fig. 10

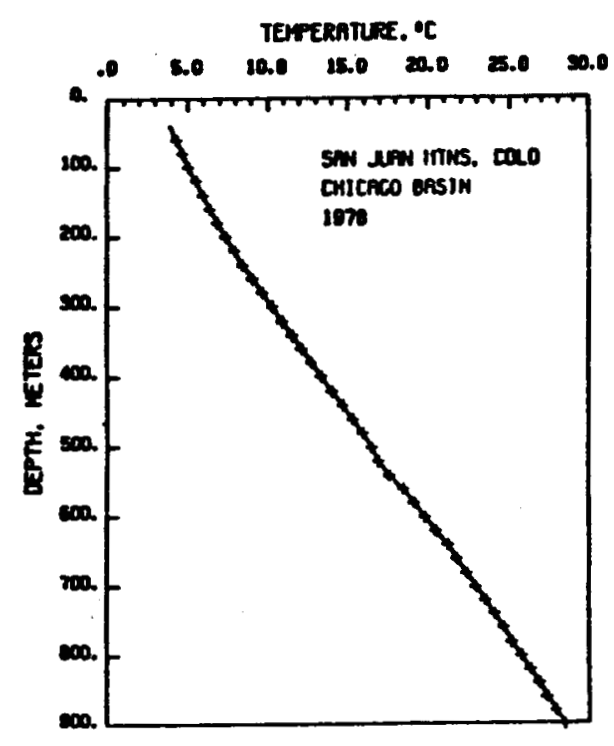

Fig. 11

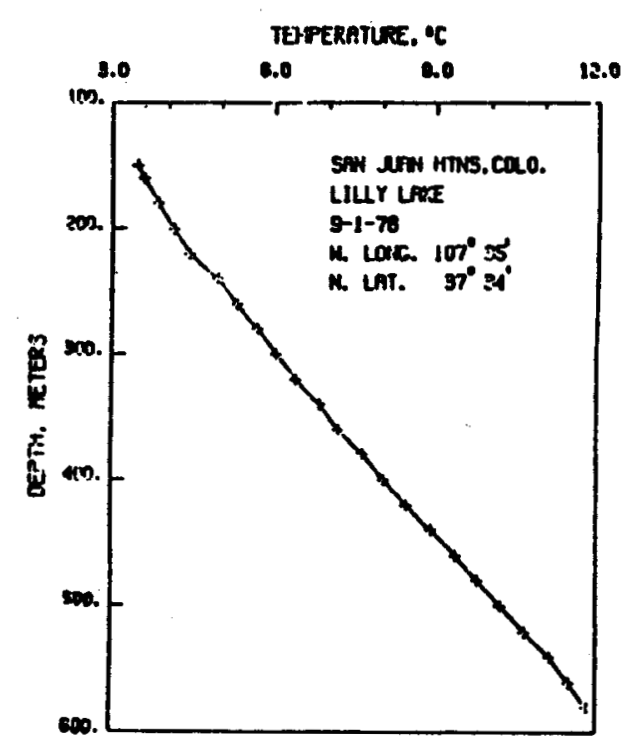

Fig. 12 


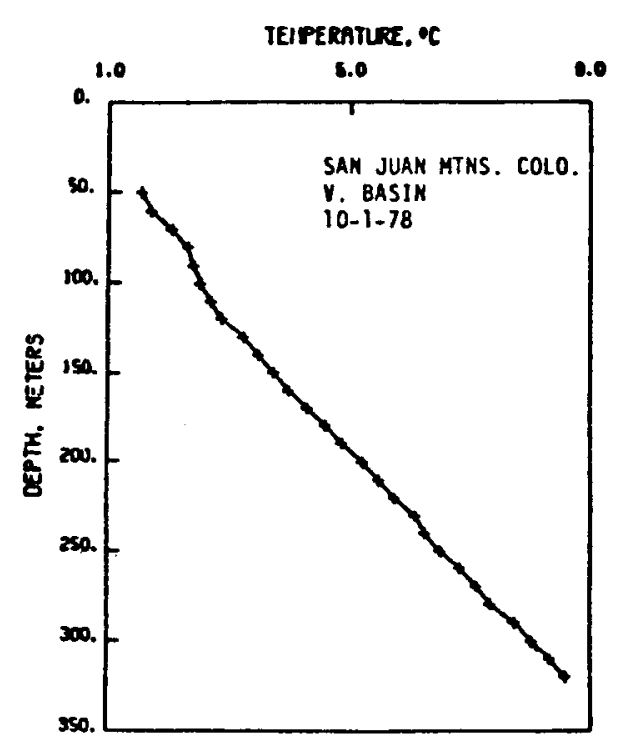

Fig. 13

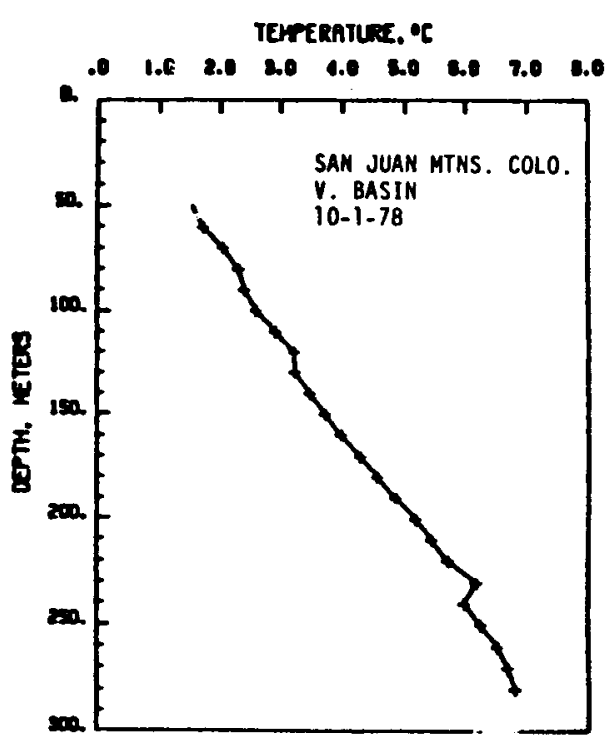

Fig. 14

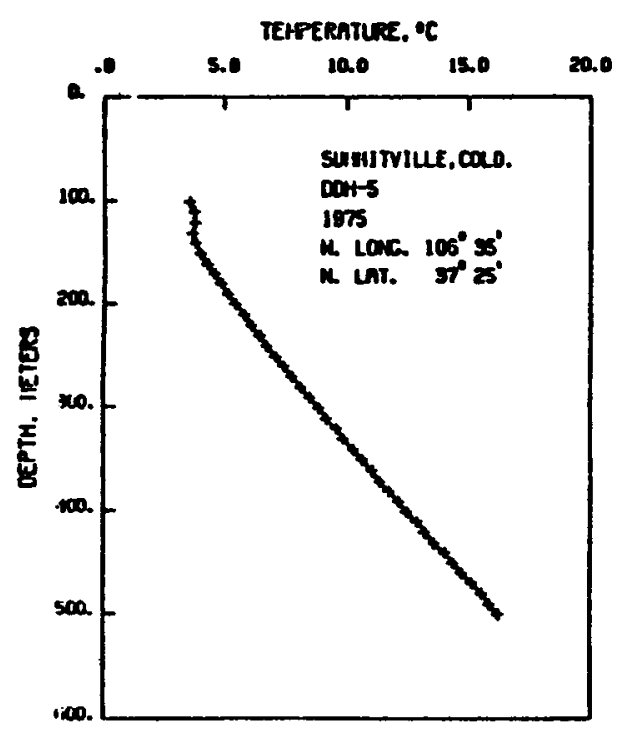

Fig. 15

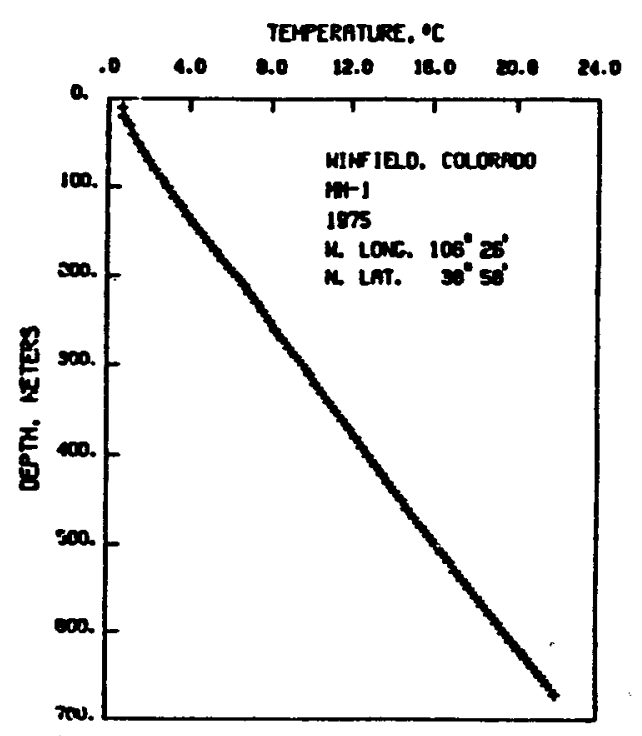

Fig. 16 


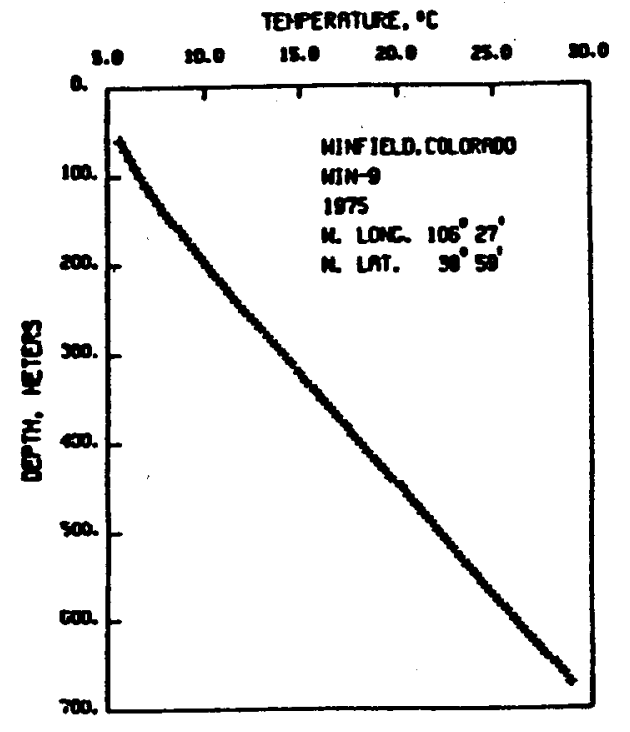

Fig. 17

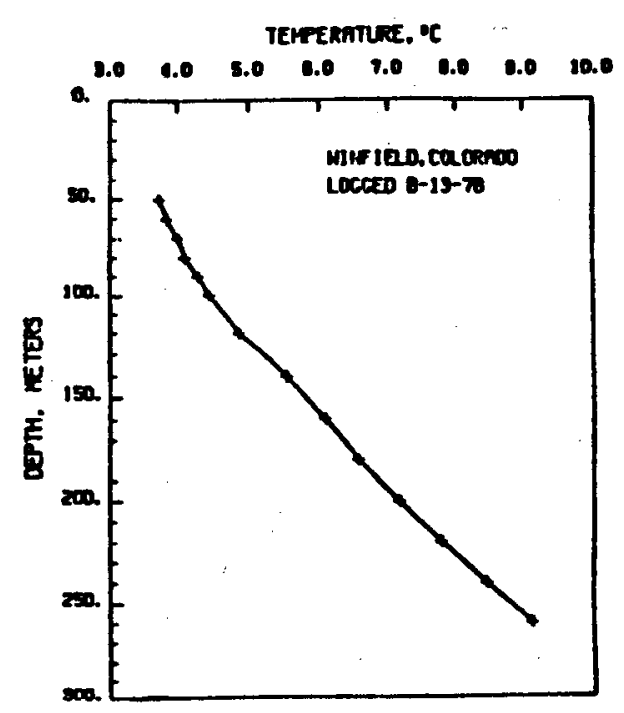

Fig. 18

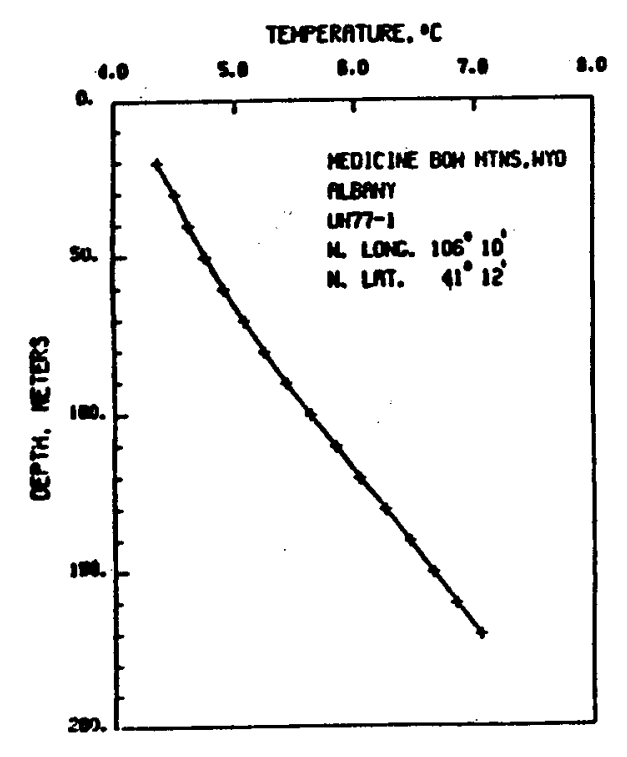

Fig. 19

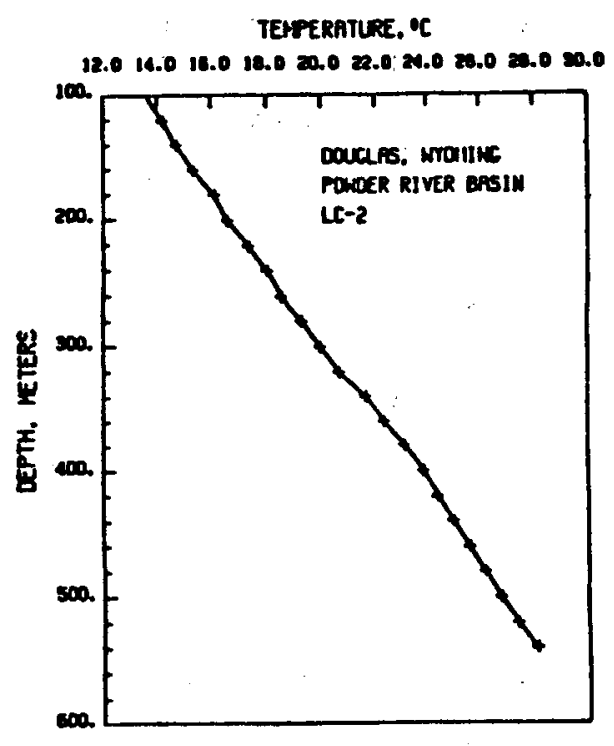

Fig. 20 


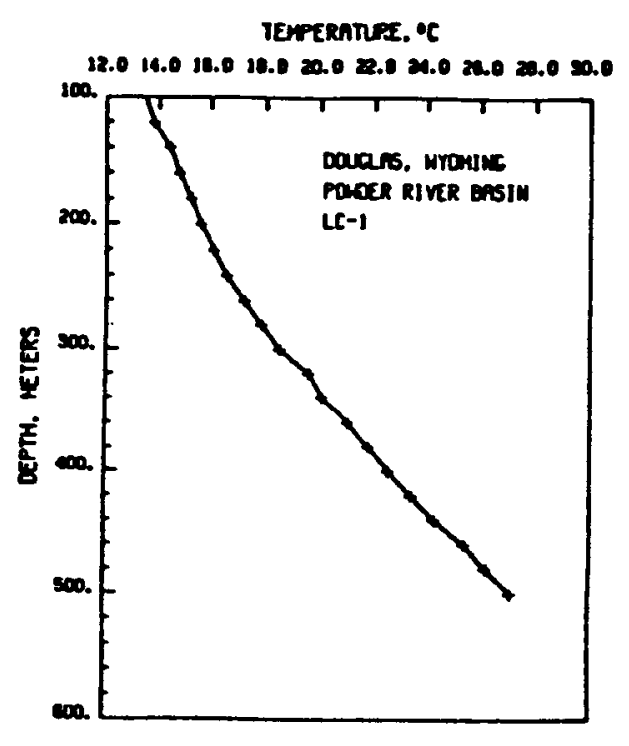

Fig. 21

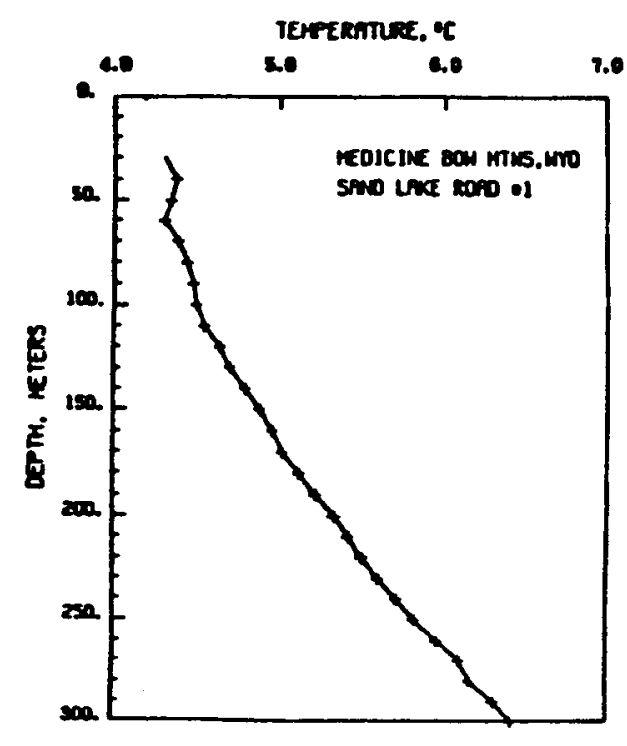

Fig. 22

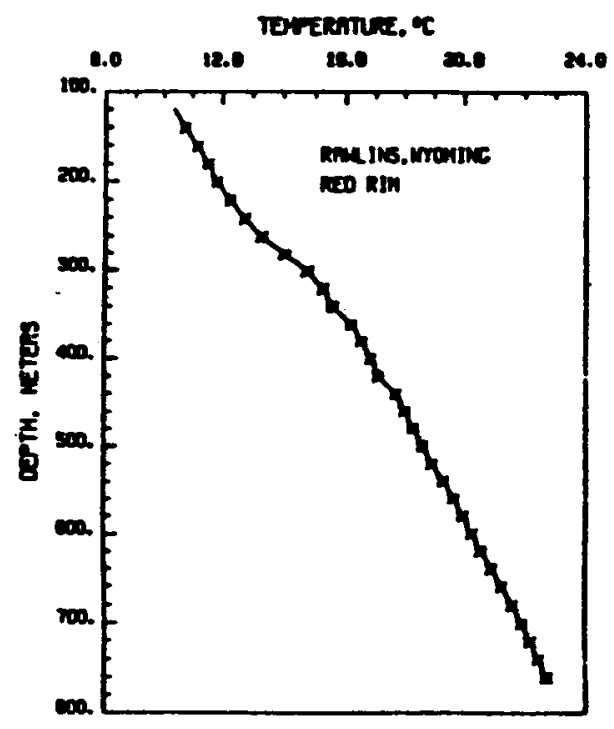

Fig. 23 
